\title{
Spatialisation of Sensible Heat Flux over a Heterogeneous Landscape
}

\author{
J.P. Lagouarde ${ }^{1}$, F. Jacob ${ }^{2}$, X.F. Gu ${ }^{2}$, A. Olioso ${ }^{2}$, J.M. Bonnefond ${ }^{1}$, Y. Kerr ${ }^{3}$, K.J. McAneney ${ }^{4}$, M. Irvine ${ }^{1}$ \\ ${ }^{1}$ INRA Bioclimatologie, BP 81, 33883 Villenave d'Ornon, France \\ ${ }^{2}$ INRA Bioclimatologie, Domaine St-Paul, Site Agroparc, 84914 Avignon cedex 9, France \\ ${ }^{3}$ CESBIO, 18 av. E. Belin, 31401 Toulouse, France \\ ${ }^{4}$ Hort Research Institute, Kerikeri, New Zealand.
}

\begin{abstract}
Two methods for retrieving sensible heat flux over a bare soil/wheat composite surface are compared within the framework of an experiment performed in June 1997 during the Alpilles/ReSeDA campaign in the South-East of France. The first one is based on field measurements using large aperture scintillometers. The principle of the method is first given and its application to composite surface discussed. The comparison against reference fluxes obtained from eddy correlation technique shows that scintillometryderived fluxes are overestimated by about $10 \%$. A numerical experiment demonstrates this is induced by aggregation problems resulting both from non linearity in the relationship between structure parameter for refractive index $\mathrm{C}_{\mathrm{N}}{ }^{2}$ and sensible heat flux $\mathrm{H}$, and from non uniform sensitivity of the scintillometer to $\mathrm{C}_{\mathrm{N}}{ }^{2}$ along the pathlength. The second method is based on the use of a simple surface energy balance model, SEBAL. The model is supplied with high spatial resolution remote sensing data from two airborne sensors in visible, near infrared and TIR bands. It provides maps of surface energy fluxes at a $20 \mathrm{~m}$ spatial sampling. A comparison against scintillometry derived fluxes (for June $9^{\text {th }}$ ) shows important discrepancies. They result from large errors in the estimation of the roughness length $\mathrm{z}_{0}$ in the model. This demonstrates that the use of an empirical relationship based on NDVI only is inadequate for inferring this key parameter in SEBAL.
\end{abstract}

\section{Introduction}

The goal of estimating and mapping surface fluxes requires simultaneous research in several domains: development of models, integration of remote sensing data, and validation of the proposed methods by field measurements. These methods must be adapted to the European landscape often characterized by a patchwork of small size fields, and must be at the same time simple and reliable enough for practical applications. The Alpilles/ReSeDA joint experiment which took place in 1997 in the South-East of France (Prévot et al., 1998) provided a good opportunity to test such approaches. In this idea we evaluated the SEBAL algorithm used in combination with high spatial resolution imagery in Visible-Near Infrared (Vis-NIR) and Thermal Infrared (TIR) domains. Obtaining fluxes directly measured at the intermediate kilometric scale for validation purposes still remains difficult: the technique of scintillometry could cover the gap presently existing between the field local scale measurements (typically the hundred of meters with micrometeorological or eddy correlation stations) and the regional scale (i.e. ten kilometers at least with airborne atmospheric measurements). Scintillometry which already revealed to provide good results for homogeneous surfaces was tested for the case of a two field-composite landscape in the Alpilles site and compared against SEBAL model results.

\section{Experimental}

The experiment was performed in June 1997 over a composite surface bare soil $(216 \mathrm{~m}) /$ wheat $(451 \mathrm{~m})$ at $\mathrm{La}$ Paillade ( $\left.43^{\circ} 47^{\prime} \mathrm{N}, 4^{\circ} 45^{\prime} \mathrm{E}\right)$ composed of 3 fields (fields 120 and 124 respectively 358 and $93 \mathrm{~m}$ long for wheat, and field 121, $216 \mathrm{~m}$ long, sown in sunflower but in bare soil conditions at the time of the experiment).

Two 'large aperture' scintillometers (LAS) were placed at 2.05 and $4.54 \mathrm{~m}$ heights between days 155 and 163. These instruments were provided by the Horticultural Research Institute (New Zealand) and are described in details in McAneney et al. (1995). Fields 120 and 121 were equipped with 3D sonic anemometers (Gill R3) and additional micrometeorological measurements were performed (air temperature and windspeed at the height of scintillometers, net radiation, ground heat flux at $5 \mathrm{~mm}$ depth). A 1D Campbell sonic anemometer was installed in field 124. The fluxes derived from scintillometers were compared against 
those estimated from eddy correlation measurements weighted by the dimension of the corresponding fields. A scheme of the experimental set up is given in Fig. 1.
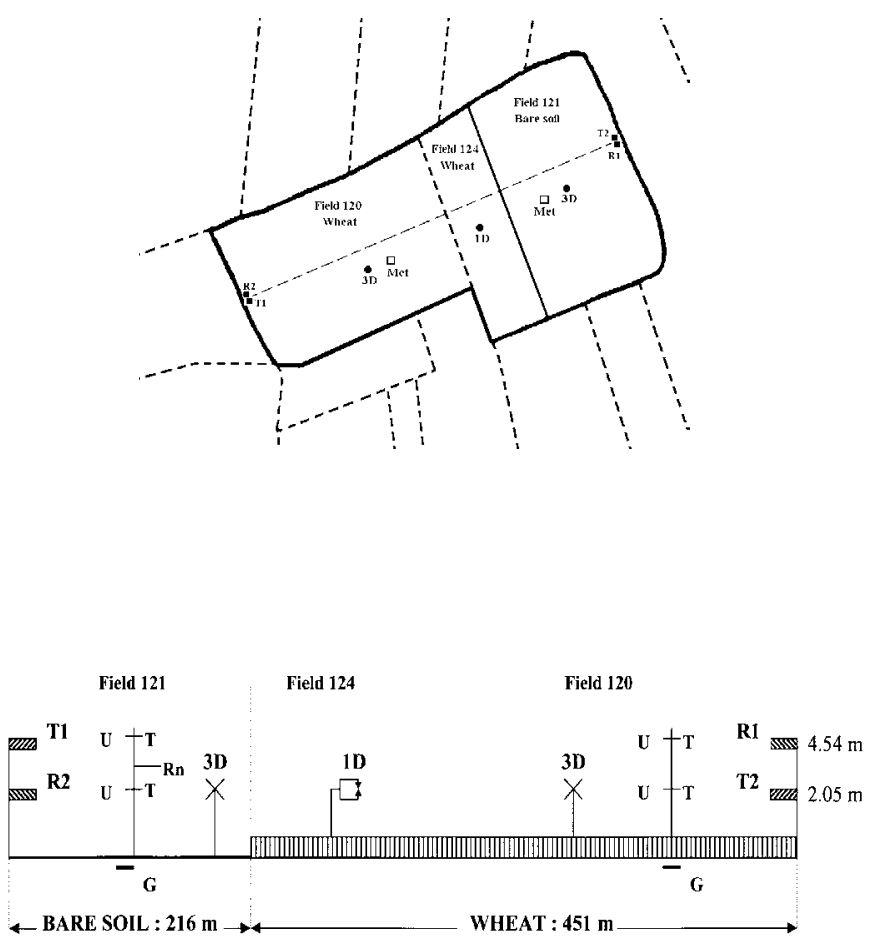

Fig.1: Experimental site and setup. (T1, R1) and (T2, R2) correspond to transmitters and receivers of scintillometers 1 and 2. 1D and 3D indicate sonic anemometers. Micrometeorological measurements (soil heat plates $\mathrm{G}$, air temperature $\mathrm{T}$, wind speed $\mathrm{U}$ and net radiation $\mathrm{Rn}$ ) are also indicated.

Airborne data were acquired using the imaging radiometer POLDER (Deschamps et al., 1994) and a thermal infrared camera INFRAMETRICS $760^{1}$, both flown aboard an aircraft on June $9^{\text {th }}$. Five flight lines were completed between 11:50 and 12:55 UTC: four of them in the principal plane, and one in the perpendicular plane. The flight altitude was about $3000 \mathrm{~m}$, yielding a $20 \mathrm{~m}$ nadir spatial resolution for both instruments. The PolDER measurements were multidirectional $\left( \pm 50^{\circ}\right)$ and performed in $20 \mathrm{~nm}$ width spectral bands centered on 443, 550, 670 and $865 \mathrm{~nm}$. Data was processed as described by Leroy et al. (2000) to derive samplings of the Bi-directional Reflectance Distribution Function (BRDF). The TIR INFRAMETRICS 760 data was acquired over the 7.25$13.25 \mu \mathrm{m}$ spectral band. After radiometric corrections and image registrations (Jacob et al., 1999 ; Gu et al., 2000), a multidirectional surface brightness temperature data set was finally provided.

${ }^{1}$ The name of companies are given for the benefit of the reader and do not imply any endorsement of the product or company by the authors.

\section{Estimation of the areally-averaged sensible heat flux by scintillometry}

\subsection{Principle}

Scintillometers provide a measurement of the structure parameter for the refractive index $\mathrm{C}_{\mathrm{N}}{ }^{2}$ derived from the analysis of the intensity fluctuations of an optical beam between a transmitter and a receiver. A review can be found in Hill (1992). We only give here a rapid overview of the method already described in details by several authors in the case of uniform surfaces (McAneney et al., 1995 ; De Bruin et al., 1995). In the optical domain, in which humidity fluctuations in the atmosphere have a much smaller influence than temperature fluctuations, the structure parameter for temperature $\mathrm{C}_{\mathrm{T}}{ }^{2}$ can be derived from $\mathrm{C}_{\mathrm{N}}^{2}$ measured by a scintillometer by:

$\mathrm{C}_{\mathrm{T}}{ }^{2}=\mathrm{C}_{\mathrm{N}}{ }^{2}\left(\frac{\mathrm{T}_{\mathrm{a}}{ }^{2}}{\gamma \mathrm{P}}\right)^{2}(1+0.03 / \beta)^{-2}$

$\mathrm{P}$ is the atmospheric pressure $(\mathrm{Pa}), \mathrm{T}_{\mathrm{a}}$ the air temperature $(\mathrm{K})$, and $\gamma$ the refractive index for air $\left(\gamma=7.910^{-7} \mathrm{~K} \mathrm{~Pa}^{-1}\right)$. $\mathrm{C}_{\mathrm{N}}{ }^{2}$ and $\mathrm{C}_{\mathrm{T}}{ }^{2}$ are in $\mathrm{m}^{-2 / 3}$ and $\mathrm{K}^{2} \mathrm{~m}^{-2 / 3}$ respectively. $\beta$ is the Bowen ratio $\beta=\mathrm{H} /(\mathrm{Rn}-\mathrm{G}-\mathrm{H}), \mathrm{Rn}$ and $\mathrm{G}$ being the net radiation and ground heat flux respectively. The temperature scale $\mathrm{T}_{*}(\mathrm{~K})$ is retrieved from $\mathrm{C}_{\mathrm{T}}{ }^{2}$ :

$\mathrm{C}_{\mathrm{T}}{ }^{2}=\mathrm{T}_{*}{ }^{2} \mathrm{z}^{-2 / 3} \mathrm{f}(\mathrm{z} / \mathrm{L})$

where $\mathrm{z}$ is the height corrected from the displacement height $\mathrm{d}$. We used the classical expressions of the f function proposed by Wyngaard (1973):

$$
\begin{aligned}
& f(z / L)=4.9\left(1+7\left|\frac{z}{L}\right|\right)^{-2 / 3} \text { for } z / L \leq 0 \text { (unstable) } \\
& f(z / L)=4.9\left(1+2.4\left|\frac{z}{L}\right|^{2 / 3}\right) \text { for } z / L>0 \text { (stable) }
\end{aligned}
$$

$\mathrm{L}$ is the Monin-Obhukov length defined as:

$$
\mathrm{L}=-\frac{\mathrm{T}_{\mathrm{a}} \mathrm{u}_{*}^{2}}{\mathrm{~kg} \mathrm{~T}_{*}} \quad \text { with } \mathrm{k}=0.4 \text { and } \mathrm{g}=9.81 \mathrm{~ms}^{-2}
$$

A wind speed measurement then allows to determine the friction velocity $\mathrm{u}_{*}$, assuming the roughness length $\mathrm{z}_{0}$ to be known, as :

$\mathrm{u}_{*}=\mathrm{ku}\left[\ln \left(\frac{\mathrm{z}}{\mathrm{z}_{0}}\right)-\Psi_{\mathrm{M}}\left(\frac{\mathrm{z}}{\mathrm{L}}\right)\right]^{-1}$ 
where $\psi_{M}$ is the classical stability function given by Panofsky and Dutton (1984).

The sensible heat flux $\mathrm{H}\left(\mathrm{Wm}^{-2}\right)$ is then computed as :

$\mathrm{H}=\rho \quad \mathrm{c}_{\mathrm{p}} \mathrm{u}_{*} \mathrm{~T}_{*}$

$\rho\left(\mathrm{kg} \mathrm{m}^{-3}\right)$ and $\mathrm{c}_{\mathrm{p}}\left(\mathrm{J} \mathrm{kg}^{-1} \mathrm{~K}^{-1}\right)$ are the air density and heat capacity respectively. $\mathrm{u}_{*}$ is in $\mathrm{m} \mathrm{s}^{-1}$. Since the sensible heat flux determines atmospheric stability, which in turn influences turbulent transport, an iterative procedure is necessary.

This method has been successfully tested in the case of homogeneous surfaces (McAneney et al., 1995 for pasture; De Bruin et al., 1995 for vineyard among others). Its application to the case of composite landscape presents with several theoretical problems:

- The assumption the Monin-Obhukov similarity theory (MOST) still holds is questionable: the physical meaning of the 'equivalent' or 'averaged' temperature scale $T_{*}$-as globally retrieved from a single scintillometer measurement over a composite pathlength- remains unclear, as well as the meaning of the friction velocity $\mathrm{u}_{*}$.

- This fundamental question apart, we are faced with several problems of aggregation which are presented below.

- Finally, despite important amount of work during the past years (Brunet at al., 1994; Itier et al., 1994), local advection which affects the transition between fields and largely depends on the combination of several factors (surface characteristics upwind and downwind, wind direction...) still remains difficult to take into account.

\subsection{Application to a composite surface}

The sensitivity of the scintillometer to $\mathrm{C}_{\mathrm{N}}{ }^{2}$ along the beam is not uniform and follows a bell-shape curve. For equal transmitter and receiver apertures, this curve is symmetrical (Fig. 2). If $\mathrm{W}(\mathrm{y})$ is the weighing function (with $\mathrm{y}$ normalized distance, i.e. $\mathrm{y}=\mathrm{x} / \mathrm{L}_{\text {beam }}, \mathrm{L}_{\text {beam }}$ being the pathlength and $\mathrm{x}$ the distance from one of its extremities) and $\mathrm{C}_{\mathrm{N}}{ }^{2}(\mathrm{y})$ the value of the structure parameter at distance $\mathrm{y}$, the average structure parameter on the optical path $\left\langle\mathrm{C}_{\mathrm{N}}{ }^{2}\right\rangle$ is given by (Wang et al., 1978):

$\left\langle\mathrm{C}_{\mathrm{N}}^{2}\right\rangle=\int_{0}^{1} \mathrm{C}_{\mathrm{N}}^{2}(\mathrm{y}) \mathrm{W}(\mathrm{y}) \mathrm{dy}$

For a two component surface which is the case studied in this paper, Eq. 8 can be written:

$\left\langle\mathrm{C}_{\mathrm{N}}^{2}\right\rangle=\mathrm{C}_{\mathrm{N} 1}^{2} \mathrm{~W}_{1}+\mathrm{C}_{\mathrm{N} 2}^{2} \mathrm{~W}_{2}$

with $\mathrm{W}_{1}=\int_{0}^{r} \mathrm{~W}(\mathrm{y}) \mathrm{dy}$ and $\mathrm{W}_{2}=\int_{r}^{1} \mathrm{~W}(\mathrm{y}) \mathrm{dy}$

$\mathrm{r}$ is the ratio of surface $1 . \mathrm{C}_{\mathrm{N} 1}{ }^{2}$ and $\mathrm{C}_{\mathrm{N} 2}{ }^{2}$ are the structure parameters for refractive index for surfaces 1 and 2 . We obviously have $\mathrm{W}_{1}+\mathrm{W}_{2}=1$. Lagouarde et al. (1995) experimentally verified Eq. (9).

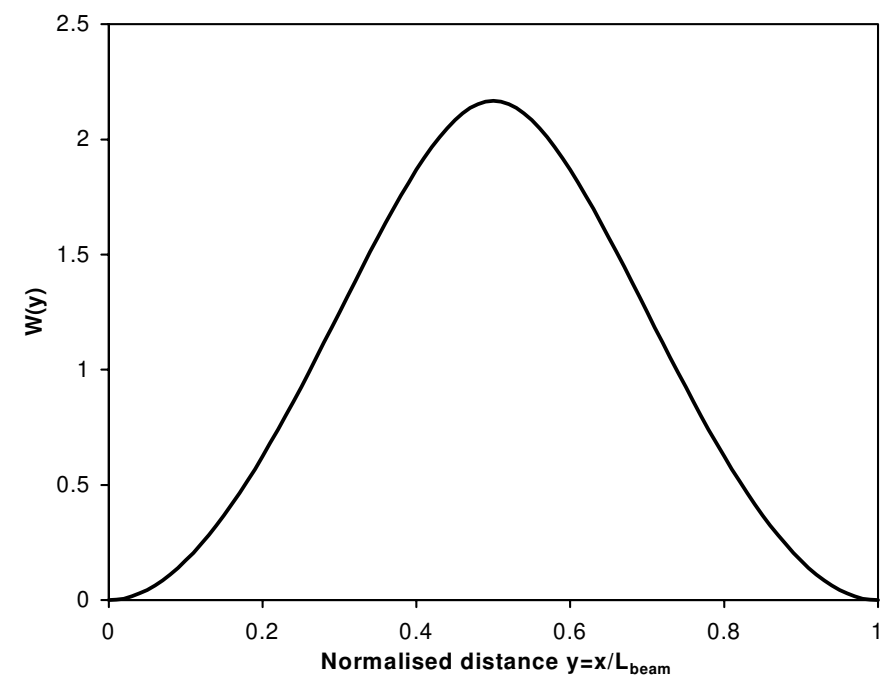

Fig. 2: weighing function of the scintillometer

Practical application of the above-described method to composite surfaces requires defining several aggregation schemes to estimate equivalent quantities (indicated by symbols $<>$ in what follows). The 2 measurements of wind speed at the same height over the two surfaces were averaged according to a scheme based on the statement that the transit time along the path length is the sum of the transit times over each surface. It leads to:

$<\mathrm{u}>=\frac{\mathrm{u}_{1} \mathrm{u}_{2}}{\mathrm{ru}_{2}+(1-\mathrm{r}) \mathrm{u}_{1}}$

$\mathrm{u}_{1}$ and $\mathrm{u}_{2}$ are the windspeed measurements over surfaces 1 and 2 .

For the displacement height, we arbitrarily considered a linear averaging of the displacement heights $d_{1}$ and $d_{2}$ over each surface:

$<\mathrm{d}>=\mathrm{rd}_{1}+(1-\mathrm{r}) \mathrm{d}_{2}$

Two aggregation schemes have been tested for roughness length. For the two surface composite case, the first one (Taylor, 1987), referred to as RL1, can be written:

$\operatorname{Ln}\left\langle\mathrm{z}_{0}>=\mathrm{r} \operatorname{Ln}\left(\mathrm{z}_{01}\right)+(1-\mathrm{r}) \operatorname{Ln}\left(\mathrm{z}_{02}\right)\right.$

According to Mason (1988) and Claussen (1991) we also examined (scheme RL2):

$\frac{1}{\left[\operatorname{Ln}\left(\frac{\mathrm{z}-<\mathrm{d}>}{\left.<\mathrm{z}_{0}\right\rangle}\right)\right]^{2}}=\frac{\mathrm{r}}{\left[\operatorname{Ln}\left(\frac{\mathrm{z}-\mathrm{d}_{1}}{\mathrm{z}_{01}}\right)\right]^{2}}+\frac{1-\mathrm{r}}{\left[\operatorname{Ln}\left(\frac{\mathrm{z}-\mathrm{d}_{2}}{\mathrm{z}_{02}}\right)\right]^{2}}$ 


\subsection{Scintillometry results}

The sensible heat flux was calculated at both levels 2.05 and $4.54 \mathrm{~m}$. The scintillometer measurements were combined with the meteorological data (wind speed and air temperature) acquired at the same heights.

The roughness lengths of wheat and bare soil were estimated from wind speed $(u)$, friction velocity $\left(u_{*}\right)$ and Monin-Obukhov length (L) values obtained from the 3D sonic anemometer measurements. We used Eq. 6 inverted and we only considered near-neutral conditions for which $-0.2 \leq \mathrm{z} / \mathrm{L} \leq 0$. We took displacement heights $\mathrm{d}=0$ for bare soil and $d=0.5 \mathrm{~m}$ for wheat. For wheat it was assessed from the canopy height $h_{c}$ as $d \sim 0.66 h_{c}$ (Brutsaert, 1982). The derived roughness length values were $\mathrm{z}_{0} \sim 0.007 \mathrm{~m}$ for bare soil and $\mathrm{z}_{0} \sim 0.10 \mathrm{~m}$ for wheat with standard deviations $0.004 \mathrm{~m}$ and $0.03 \mathrm{~m}$ respectively. These are consistent with general experience, and the value found for wheat perfectly fits the classical rule-of-thumb $\mathrm{z}_{0} \sim 0.13 \mathrm{~h}_{\mathrm{c}}$ for dense vegetation canopies.

The comparison between sensible heat flux obtained by scintillometery against reference values $\mathrm{H}_{\text {ref }}$ is presented in Fig. 3. $\mathrm{H}_{\mathrm{ref}}$ is the average of the measurements of sensible heat flux weighed by the ratio of the corresponding fields: $\quad \mathrm{H}_{\mathrm{ref}}=0.537 \mathrm{H}_{120}+0.139 \mathrm{H}_{124}+0.324 \mathrm{H}_{121}$. The comparison of the two wheat fields revealed that field 124 was a little drier than 120: we found a regression $\mathrm{H}_{124(1 \mathrm{D})}=1.153 \mathrm{H}_{120(3 \mathrm{D})} \quad\left(\mathrm{r}^{2}=0.893, \quad \mathrm{rmse}=34.0 \quad \mathrm{Wm}^{-2}\right)$. This relation was used to extrapolate a few missing data in field 124.

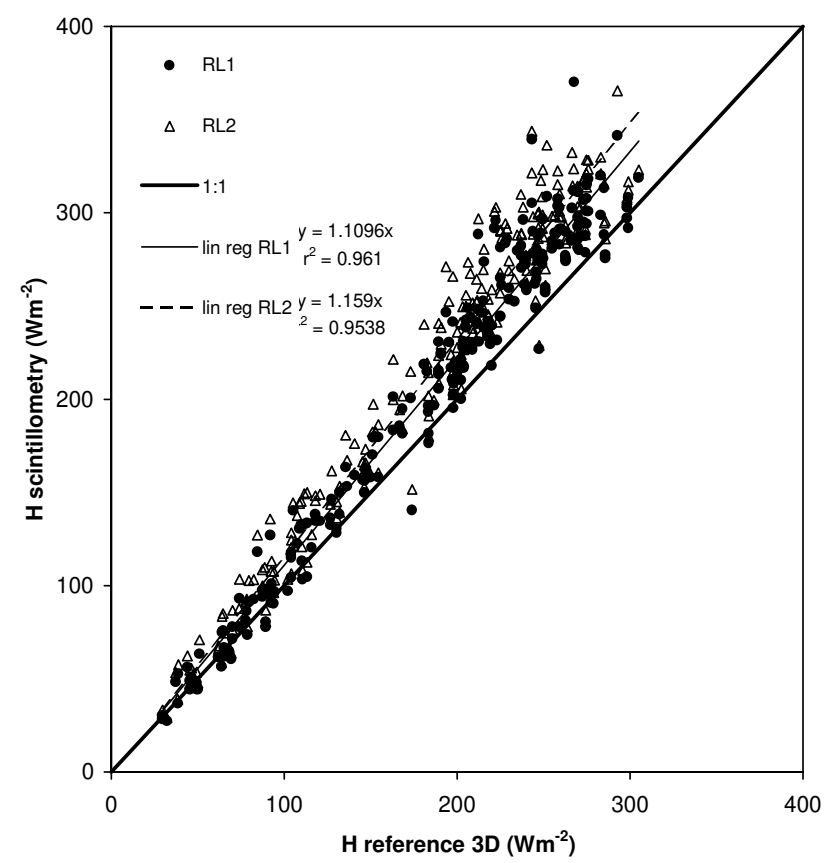

Fig. 3: Comparison between spatially-averaged sensible heat flux derived from eddy correlation measurements and from scintillometry, using 2 aggregation schemes for roughness length.
We observed a systematic bias with an overestimation of the scintillometer derived flux by about $11 \%$ and $16 \%$ for aggregation schemes RL1 and RL2 respectively. We did not notice significant sensitivity to measurement height nor to wind direction. After careful investigations not described in details here (intercalibration of instruments, analysis of the possible contribution of low frequencies in the 3D sonic anemometers measurements particularly...) we could not find any obvious experimental reason able to explain either overestimation of $\mathrm{H}$ by scintillometers or underestimation by sonic anemometers. The bias observed in Fig. 3 is therefore likely not to be an artefact, and we suspected that the aggregation process of the $\mathrm{C}_{\mathrm{N}}{ }^{2}$ along the beam could be responsible for it. As a matter of fact it includes several sources of non-linearity: non-linearity of the relationship between $\mathrm{H}$ and $\mathrm{C}_{\mathrm{N}}{ }^{2}$, and non-linearity of the scintillometer sensitivity along the beam.

\subsection{Simulation}

We assumed a composite area including 2 surfaces. The principle consisted in computing the structure parameter $\mathrm{C}_{\mathrm{N} 1}{ }^{2}$ and $\mathrm{C}_{\mathrm{N} 2}{ }^{2}$ for both surfaces from prescribed values of parameters (roughness length and displacement height which were given different values according to the surfaces), micrometeorological variables (air temperature and wind speed at $10 \mathrm{~m}$, assumed uniform over the composite area), and fluxes $\mathrm{H}_{1}$ and $\mathrm{H}_{2}$. The computations successively consisted of (i) estimating $\mathrm{u}_{*}$ from Eq. 6 (an iterative procedure is here necessary as $\mathrm{u}_{*}$ appears in the expression of $\mathrm{L}$ ), (ii) deriving $\mathrm{T} *$ from Eq. 7, Eq. 2 and 1 finally providing $\mathrm{C}_{\mathrm{T}}^{2}$ and $\mathrm{C}_{\mathrm{N}}{ }^{2}$. The 2 estimated structure parameters $\mathrm{C}_{\mathrm{N} 1}{ }^{2}$ and $\mathrm{C}_{\mathrm{N} 2}{ }^{2}$ were then weighed according to the bell-shape sensitivity curve of the scintillometer (Eq. 9) to simulate the scintillometer-measured $\mathrm{C}_{\mathrm{N}}{ }^{2}$ from which a value of sensible heat flux $\mathrm{H}_{\text {sim }}$ was derived (as described in section 3.1). This was finally compared to the reference precribed $\mathrm{H}_{\text {presc }}$ value consisting of the linear weighing of the initially prescribed fluxes $\mathrm{H}_{\text {presc }}=\mathrm{r} \mathrm{H}_{1}+(1-\mathrm{r}) \mathrm{H}_{2}$.

\begin{tabular}{lcc}
\hline & RL1 & RL2 \\
\hline Field data & 1.110 & 1.159 \\
Simulation & 1.055 & 1.105 \\
\hline
\end{tabular}

Table I: Slope of the regression lines obtained when comparing $\mathrm{H}$ estimates for experimental data (comparison between scintillometry and eddy correlation measured $\mathrm{H}$ ) and for simulation (comparison between simulated and prescribed $\mathrm{H}$, see text).

Fig. 4 displays the results obtained when giving both surfaces the actual values of parameters $z_{0}$ and $d$, and the variables $\left(\mathrm{H}_{1}, \mathrm{H}_{2}\right.$, micrometeorological data) measured at every time step during the experiment. The bias we already noted is still visible. As it can be seen in Table I giving the slopes of the different regression lines, it is by about $5 \%$ lower than the one found from the field experiment. Nevertheless as the simulation procedure obviously eliminates the influence of any possible instrumental error, it confirms the sensitivity of scintillometer measurements to 
aggregation problems in the case of a composite area. The bias jointly depends on the ratio of surfaces, on the difference of their aerodynamic characteristics (mainly roughness) and on the contrast in their water status. A systematic study based on numerical experiments -not presented here- has been undertaken to assess the influence of each of these factors.

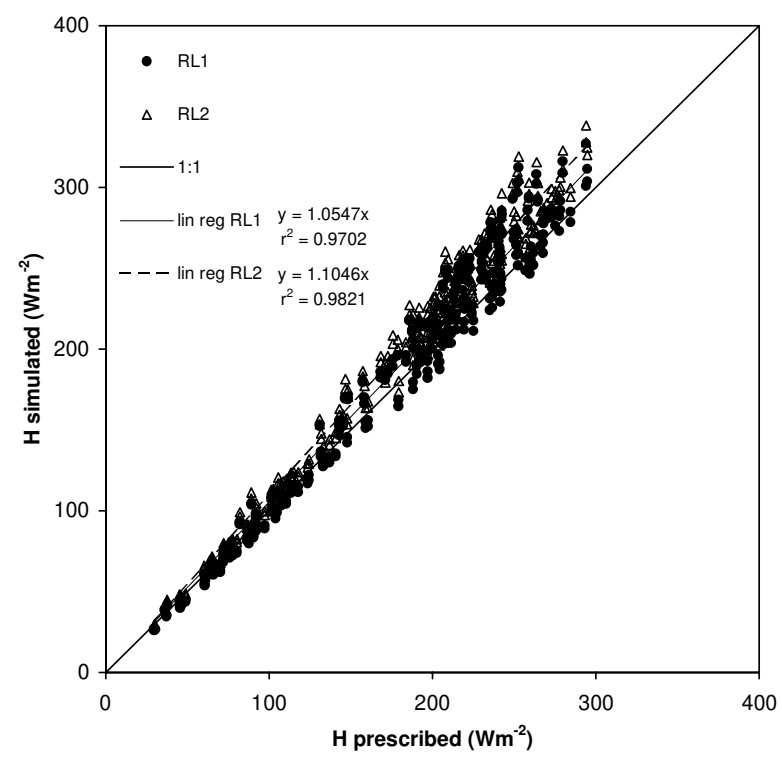

Fig. 4: Simulation of the scintillometer response for a twosurface composite pathlength: comparison between simulated and prescribed areally-averaged sensible heat flux.

\section{Estimation of the sensible heat flux using the SEBAL model}

\subsection{Description of the model}

The single layer SEBAL model (Surface Energy Balance Algorithm for Land, Bastiannssen et al., 1998) aims at mapping surface energy fluxes using exclusively multispectral remote sensing data. Its interest is to estimate both the wind speed and air temperature from the information contained in the spatial variability. This assumes that the study area includes sites with very high and very low evapotranspiration. The model requires maps of NDVI (Normalized Difference Vegetation Index), albedo and surface brightness temperature. It computes the surface energy fluxes at the same spatial resolution than input maps. A more detailed description of SEBAL can be found in Jacob et al. (2000). Note only here that the roughness length is estimated from NDVI through a semi-empirical relationship (Bastiaanssen et al., 1998).

\subsection{SEBAL results}

The multidirectional PolDER data were used with BRDF kernel-driven models to compute both the nadir and hemispherical reflectances. NDVI was calculated as the normalized difference between the 865 and $670 \mathrm{~nm}$ nadir reflectances. Albedo was computed as a linear combination of the hemispherical reflectances in the four PolDER channels (Weiss et al., 1999). To provide the surface brightness temperature maps, we averaged the INFRAMETRICS 760 data corresponding to nadir view angles lower than $20^{\circ}$. SEBAL maps of sensible heat fluxes showed a strong spatial variability for heterogeneous fields, and the pattern of the whole site at a larger scale. A more detailed description of the methods used to derive the SEBAL input variables can be found in Jacob et al. (2000), as well as a comparison of model outputs against field measurements .

We then computed averaged values of the SEBAL derived sensible heat fluxes over the fields 120, 121, 124 (after elimination of the edges possibly contaminated by adjacent fields) and along the scintillometer optical path (Fig.5). The ratio of the averaged values between fields 124 and 120 was about 1.14, which was close to eddy correlation measurements (Sect. 3.3). Table II displays the comparison between SEBAL and ground measurements for fields 120 and 121 independently, and then integrated along the scintillometer optical path. A first simulation performed with the initial version of the SEBAL model led to a very large underestimation of $\mathrm{H}_{\text {path. }}$. This was clearly related to erroneous estimation of $\mathrm{H}_{120}$ over wheat. As the model estimates of the net radiation and of the difference between surface and air temperatures were correct, the origin of the discrepancy on $\mathrm{H}_{120}$ could only be found in the unrealistic estimate of $\mathrm{z}_{0}$ provided by SEBAL : $0.01 \mathrm{~m}$ to be compared against the $0.1 \mathrm{~m}$ reference value derived from $3 \mathrm{D}$ eddy correlation measurements. The reason is obviously the failure of the semi-empirical relationship between $\mathrm{z}_{0}$ and NDVI in our case: at the beginning of the senescence phase, the drying wheat keeps its structure (height, leaves...) and hence its roughness, but displays dramatic decrease in NDVI. This was confirmed by a second simulation in which the roughness lengths for wheat and bare soil were prescribed to the reference values, 0.1 and $0.007 \mathrm{~m}$ respectively: the agreement obtained on $\mathrm{H}_{\text {path }}$ is much better (see Tab. II).

\begin{tabular}{|c|c|c|c|}
\hline & $\begin{array}{c}\mathrm{H}_{120} \\
\text { Wheat }\end{array}$ & $\begin{array}{c}\mathrm{H}_{121} \\
\text { Bare soil }\end{array}$ & $\begin{array}{c}\mathrm{H}_{\text {path }} \\
\text { Optical path }\end{array}$ \\
\hline Eddy correlation & 303.1 & 188.6 & 273.0 \\
\hline Scintillometer & - & - & 296.9 \\
\hline $\begin{array}{l}\text { SEBAL } \\
\text { (initial version) }\end{array}$ & 122.1 & 174.5 & 141.4 \\
\hline $\begin{array}{l}\text { SEBAL } \\
\text { ( } \mathrm{z}_{0} \text { prescribed) }\end{array}$ & 242.8 & 205.6 & 240.9 \\
\hline
\end{tabular}

Table II: comparison between reference eddy correlation, scintillometry, and SEBAL estimates of sensible heat flux for fields 120 and 121 and integrated over the scintillometer pathlength. 


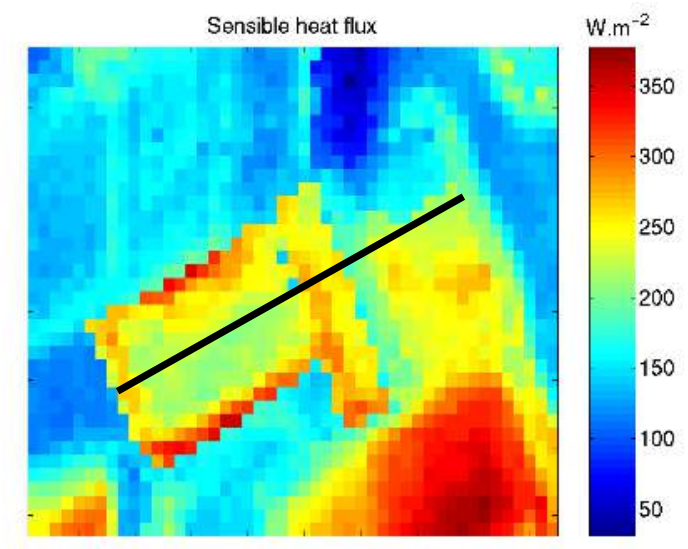

Fig. 5: SEBAL derived sensible heat flux for fields 120 , 121 and 124. The black line corresponds to the scintillometer optical path.

\section{Conclusion}

In this paper two methods for inferring spatially-averaged sensible heat flux have been tested. For the simple case of a two-surface composite landscape, scintillometry provided slightly overestimated values compared to reference eddy correlation measurements by about $10 \%$. A simple model of the scintillometer response confirmed that the deviation results from non linearities in the aggregation process of the scintillometer signal along the optical path. This model is currently being used to study the sensitivity of scintillometer measurements to the characteristics of the surface (composition, contrasts in water status and roughness between plots), with the scope of developing corrections for the bias in $\mathrm{H}$. The very large discrepancies observed between reference $H$ values (from eddy correlation) and the SEBAL model derived ones were attributed to errors in the estimates of roughness length rising from the inadequacy of the semi-empirical relationship between NDVI and $z_{0}$ used. This example once more illustrates the well-known difficulty of finding a satisfactory compromise between the simplifications of models brought by the use of very coarse parameterizations and their accuracy.

\section{Aknowledgments}

The Alpilles-ReSeDA project was funded by the EEC-DG XII and by the French Programme National de Télédétection Spatiale and Programme National de Recherches en Hydrologie. The IRSA-MARS project provided access to ground data and SPOT images. The POLDER airborne sensor was provided by the LOA (Lille, France). The authors also thank the Horticultural Research Institute (New Zealand) who provided the scintillometers and experimental support.

\section{References}

Bastiaanssen W.G.M., Menenti M., Feddes R.A., Holtslag, A.A.M., 1998: A remote sensing surface energy balance algorithm for land (SEBAL). 1. Formulation. Journal of Hydrology, 212-213, 198-212.
Brunet Y., Itier B., McAneney K.J., Lagouarde J.P., 1994: Downwind evolution of scalar fluxes and surface resistance under conditions of local advection. Part II: measurements over barley. Agric. For. Meteor., 71, 3-4, 227-245.

Brutsaert W., 1982: Evaporation into the atmosphere. Theory, History and Applications. D. Reidel publishing Company, Dordrecht, Holland. 299 p. Claussen M., 1991: Estimation of areally-averaged surface fluxes. Bound.Layer Meteorol., 54, 387-410.

De Bruin H.A.R., Van den Hurk B.J.J.M., Kohsiek W., 1995: The scintillation method tested over a dry vineyard area. Boundary-Layer Meteorol., 76, 25-40.

Deschamps P.Y., Bréon F.M., Leroy M., Podaire A., Bricaud A., Buriez J.C., Sèze G., 1994: The PolDER mission: instrument characteristics and scientific objective. IEEE Transaction on geosciences and Remote Sensing, 32, 598-615.

Gu X.F., Jacob F., Hanocq J.F., 2000: Acquisition and preprocessing of INFRAMETRICS airborne thermal infrared data during the ReSeDA Experiment. EGS Symposium, special ReSeDA session, Nice. Submitted to Physics and Chemistry of the Earth.

Hill R.J., 1992: Review of optical scintillation methods of measuring the refractive-index spectrum, inner scale and surface fluxes. Waves in Random Media, 2, 179-201.

Itier B., Brunet Y., McAneney K.J., Lagouarde J.P., 1994: Downwind evolution of scalar fluxes and surface resistance under conditions of local advection. Part I: a reappraisal of boundary conditions. Agric. For. Meteor., 71, 3-4, 211-225.

Jacob F., Gu X.F., Hanocq J.F. Baret F., 1999: A procedure for atmospheric corrections of single channel and multidirectional thermal infrared data. Application to the ReSeDA experiment. Submitted to International Journal of Remote Sensing.

Jacob F., Olioso A., Gu X.F. Leroy M., Hautecoeur O., Hanocq J.F., 2000: Mapping surface fluxes using visible - near infrared - thermal infrared data and the SEBAL algorithm. EGS Symposium, special ReSeDA session, Nice. Submitted to Physics and Chemistry of the Earth.

Lagouarde J.P., McAneney K.J., Green A.E., 1996: Spatially-averaged measurements of sensible heat flux using scintillations: first results above a heterogeneous surface. "Scaling-up in Hydrology using remote sensing" workshop, June 10-12 1996, Institute of Hydrology, Wallingford, G.B., Wiley \& sons Ed., 147-160.

Leroy M., Hautecoeur O., Berthelot B., Gu X.F., 2000: The airborne PolDER data during the ReSeDA experiment. EGS Symposium, special ReSeDA session, Nice. Submitted to Physics and Chemistry of the Earth. Mason P.J., 1988: The formation of areally-averaged roughness lengths. Quart. J. Roy. Meteor. Soc., 114, 399-420.

McAneney, K.J., Green, A.E. Astill, M.S., 1995: Large-aperture scintillometry: the homogeneous case. Agric. and Forest Meteor., 76, 149-162.

Panofsky H.A., Dutton J.A., 1984 : Atmospheric turbulence: models and methods for engineering applications. John Wiley \& Sons, New York.

Prévot et al.,1998: Assimilation of multi-sensor and multi-temporal remote sensing data to monitor vegetation and soil: the Alpilles-ReSeDA project. IGARSS'98, International Geoscience and remote Sensing Symposium, Ed. L. Tsang, Seattle, 17-30.

Taylor P.A., 1987: Comments and further analysis on effective roughness lengths for use in numerical three-dimensional models. Bound.-layer Meteor., 39, 403-418.

Wang Ting-i, Ochs G.R., Clifford S.F., 1978: A saturation-resistant optical scintillometer to measure $\mathrm{C}_{\mathrm{N}}^{2}$.J. Opt. Soc. Am., 68 334-338.

Weiss M., Baret F., Leroy M., Bégué A., Hautecoeur O., Santer R., 1999: hemispherical reflectance and albedo estimate from the accumulation of across-track sun-synchronous satellite data. Journal of Geophysical Research, 104, 2221-2232.

Wyngaard J.C., 1973: On surface-layer turbulence. Workshop on Micrometeorology, Denver, Colorado, Amer . Meteor. Soc., 101-149. 